DOI: 10.12731/2077-1770-2019-2-228-240

УДК 140.8

\title{
ФОРМЫ РАЦИОНАЛЬНОСТИ В ФИЛОСОФИИ М. ФУКО
}

\section{Щеров В.И.}

Цель. В статье исследуется проблема объяснения ращиональных видов познания в современной философии. Понятию рациональности придается научно-теоретический, феноменологический и культурологический контекст. На примере работ М. Фуко анализируются исторические формы раџиональности. Ращиональный дискурс представлен как лингвистическая модель, определяющая познавательную практику в политике, медицине, искусстве, образовании.

Метод или методология проведения работы. Для изучения рациональных форм познания в статье используется структурный метод на примере оппозиций «слова/вещиџ», «видимое/говоримое», «разумность/неразумие» и т. д. В работах М. Фуко каждая из этих структур содержит невысказанный, избыточный и несформулированный остаток мысли.

Результаты. В статье выявлена антропологическая значимость классической и неклассической форм рациональности. Рациональность рассмотрена не как научно-теоретический дискурс, а как явление культуры.

Область применения результатов. Результать исследования могут быть использованы в историко-философских исследованиях по современной научной методологии.

Ключевые слова: дискурс; постструктурализм; рациональность; структурная оппозищия «слова/вещиџ»; эпистема.

\section{FORMS OF RATIONALITY \\ IN THE PHILOSOPHY BY M. FOUCAULT}

\section{Shcherov V.I.}

Purpose. The article examines the problem of explaining rational types of knowledge in modern philosophy. The concept of rationality is attached 
to the scientific-theoretical, phenomenological and cultural studies context. On the example of the works of $M$. Foucault historical forms of rationality are analyzed. Rational discourse is presented as a linguistic model that determines cognitive practice in politics, medicine, art, and education.

Methodology. In order to study rational forms of knowledge, the article uses the structural method on the example of the opposition "words / things", "visible / spoken", "rationality / unrationality" etc. In the works of M. Foucault, each of these structures contains an unspoken, redundant and unstated residue of thought.

Results. The article reveals the anthropological significance of classical and non-classical forms of rationality. Rationality is considered not as a scientific theoretical discourse, but as a cultural phenomenon.

Practical implications. The results of the study can be used in philosophical research on modern scientific methodology.

Keyword: discourse; poststructuralism; rationality; structural opposition "words / things"; episteme.

Одной из незавершенных дискуссий в западной и отечественной философии является проблема трактовки рациональности. Поиски наиболее полного определения разумности были начаты Р. Декартом в XVII веке и сводились к методу и критериям научной истинности. Этот образец знания, базировавшийся на принципах детерминизма, механизма, телеологизма, абсолютизации результатов познания и т. д., получил название классического [15, с. 41]. В XX веке такому метафизического пониманию рациональности противопоставляется новый стиль мышления в виде неклассической модели знания, сотканной из установок условности, релятивизма, контекстуальности, нелинейного эволюционизма и др. [15, с. 42-43].

В этот же период понятие рациональности, благодаря исследованиям М. Вебера, также проникает и в область наук социологических, подразумевая экономическую и ценностную упорядоченность индустриального общества $[1$, с. 55]. В отечественной философии М.К. Мамардашвили противостояние классической и неклассической модели рациональности переносит в область познавательных 
стратегий и «феноменологического слоя» сознания, где кристальная ясность картезианского мышления непримиримо сталкивается с явлениями непонятности, неконтролируемости, спорадичности [5, с. 54-56]. Психологизм М. Мамардашвили исследует внутренние механизмы сознания, и в меньшей степени его социальную и историческую ангажированность.

Другой отечественный философ, академик В. С. Степин, в 80-е годы уже с опорой на деятельностный подход помимо методической систематизации знакомых классической и неклассической моделей научного познания вводит третий вид рациональности - постнеклассический. Эта модель научного мышления ставит на первое место антропный принцип, согласно которому любой вид знания становится средством обслуживания потребностей человека внутри саморазвивающихся систем природы, техники, общества, а наука всегда предваряется ценностными установками. В.С. Степин вводит критерии для оценки всех трех типов научной рациональности: «...научное познание может быть охарактеризовано посредством связей и отношений между осваиваемым объектом, субъектом деятельности, а также используемыми им средствами и операциями деятельности» [2, с. 249]. Они нам необходимы для рассмотрения необычных моделей рациональности, предложенных французским структуралистом М. Фуко.

Прежде всего, М. Фуко расширяет значение рациональности, выводя её за границы научного или феноменологического опыта. Рациональность для него приобретает языковую форму дискурса, который формируется в культурологическом контексте различных исторических эпох. Первым в европейской истории значительным дискурсом о Разуме, Логосе М. Фуко называет платоновские рассуждения об истинном пути познания мира идей. Платоновский дискурс о демиурге, врожденных идеях, анамнесисе, подобии мира идей и мира вещей определил дальнейшее развитие метафизики. Античное разграничение рационального и чувственного познания в одной из первых работ Фуко «Рождение клиники» приобретает вид структурной оппозиции «говоримого/видимого». Метод был заим- 
ствован Фуко из структурной лингвистики и в дальнейшем применялся им для анализа неоднозначных явлений культуры.

В работе «Слова и вещи. Археология гуманитарных наук» Фуко изучает новую антропоцентрическую традицию рационального знания, сложившуюся в эпоху Возрождения и получившую развитие в Новое время и современности. Начиная с Ренессанса, рациональный дискурс М. Фуко представляет в виде трех моделей «эпистемы», включающих различные комбинации структуры «слова/ вещи». Оформление дискурса связывается с изменением значения языка в культуре. В эпоху Возрождения с культом книги язык рассматривался как вещь среди вещей. Во времена классического рационализма язык - средство выражение картезианской мысли. В современности приобретение знание осуществляется уже внутри самого языка с его условностью референтов и самоинтерпретациями [12, с. 355$]$.

Определяя эти образцы рациональности Фуко в тоже время утверждал, что любой философский дискурс прошлого содержит в себе некий невысказанный, избыточный и несформулированный остаток мысли. В каждом из них Фуко видит несоответствия и незавершенность строгой рациональной структуры, полагаясь в определении своей «диспозиции» на почти ницшеанскую волю к знанию или истине. Он причислял себя к философскому направлению постструктурализма, и каждая его новая книга содержала «проблематизацию» познания очередного структурного противостояния. Рациональность рассматривается как дискурс или текст. Но текст как знаковая система в своей синхронной и диахронной корреляции с реальностью или временем оказывается не однозначен. Это не означает, что дискурс теряет понятийную последовательность и ясность, но у «первичного» текста появляются комментарии в виде их «вторичного» воспроизводства, «...чтобы сказать наконец то, что безмолвно уже было высказано там» [6, с. 62].

Фуко намеренно не обращается к общеизвестным метафизическим трактатам прошлого, чтобы не оказаться вовлеченным в эпицентр эпистемологических или методологических споров. Ему 
гораздо важнее понять историческую ангажированность дискурса и его неоднозначное понимание (комментирование) современниками. Рациональный дискурс интересен не только безусловно непротиворечивым содержанием, но и социальным влиянием. В этом смысле регламентирующие тексты в области политики, морали, права, воспитания, медицины, которые напрямую организуют историческую реальность и общественную жизнь, гораздо полнее представляют рациональность, чем спекулятивное или теоретическое рассуждение. Интерес Фуко к историческим документам во много опровергает обвинения в адрес структуралистов об их лингвистической одержимости.

Прежде всего, если классическая и неклассическая модели рациональности основывались на установлении господствующего в науке метода и цели познания, то Фуко все формы рациональности выводит из исторически сложившихся метафизических дискурсов. Но это не схоластическая игра идеи и вещи (universalia ante res, universalia in res, universalia post res), а традиция антропологических интерпретаций соотнесения Разума (Логоса, языка) и телесного мира вещей, начатая еще Платоном и продолжавшаяся до современности. Во-вторых, если научные модели рациональности строятся на поиске доопытных и объективных принципов мышления, то Фуко концентрируется на результатах воплощения рационального дискурса в соответствующих социальных условиях. В-третьих, Фуко в рассуждениях о разумности обращается не к теоретическим закономерностям научного познания, а к сложившимся в определенную историческую эпоху непредсказуемым дискурсивным практикам в области политики, воспитания, литературы, медицины и т. д. Дискурс как знаковая система, в отличие от математически ясной логической аксиоматики, позволяет ссылаться на интертекстуальные комментарии или скрытые коннотации.

У рациональных моделей лингвистических «эпистем» присутствует обратная связь с практикой познания телесного и предметного. Например, классический тип мышления Нового времени, подражающий аристотелевской истине, отождествляющей знание 
о вещи и саму вещь, у Фуко представлен познавательной структурой «видимого/говоримого» [11, с. 176] как медицинской аналогией с телесной симптоматикой и заболеванием («Рождение клиники» (1963 г.)). Клинический взгляд врача должен соединить в себе наблюдение за внешними проявлениями больного и вызвавшими их внутренними патологиями. Установление правильного диагноза - это и есть момент рационального единства явления и сущности. Современный тип лингвистической «эпистемы», где язык становится самодостаточной познавательной средой, представлен в работах Фуко о литературе «Что такое автор?» (1969 г.) и об искусстве «Это не трубка» (1973 г.) Можно ли установить аутентичность литературного текста вне интертекстуальных связей? Для Фуко это будет затруднительно, если учесть творческую эволюцию автора, влияние на него других писателей, разнонаправленность черновых рукописей, инвариант сюжета, заметки на полях, фиксированные «следы» биографии и т. д. Автор в лингвистической среде - условная величина стилистического единства, названия книги, теории, закона, возможно, материал для другого текста [6, с. 27]. Произведение обретает рациональную форму из сплетения всех этих спонтанных факторов и взаимовлияний. Не менее парадоксальным у Фуко в работе «Это не трубка» оказывается восприятие художественной формы в искусстве на примере сюрреалистической живописи Р. Магритта. Картина может стать тем место, где утрачивается феноменологическое единство явления и сущности, воспринимаемых образов и их языкового обозначения. Воображаемый мир сюрреалистической картины, сотканный из связи изображенных силуэтов персонажей, фрагментов, контуров и пр. не всегда можно обозначить точной знаковой формой; она всегда будет нести в себе многозначность в силу неопределенности этих связей. В том и состоит творчество художника, чтобы живопись создавала условия для порождения множественных, иногда взаимоотрицающих значений [13, с. 50].

Другой стороной рационалистических дискурсов М. Фуко является их культурологическое и социальное значение. В рамках 
выстаиваемых им дискурсивных систем помещались краеугольные камни культуры: законы, религия, воспитание и т. д. В процессе социализации каждый человек подвергается наставительным формам внешнего воздействия в виде дисциплины, наказания, уставных ограничений. Под особым надзором со стороны общества (государства) находятся такие области человеческой деятельности, как труд (экономическое производство), семья (воспроизводство общества), речь (языковая коммуникация) и игра (культурные ценности в виде празднеств, исторических традиций, художественного творчества) $[12$, с. 4]. В насаждении дискурса власти особое место занимают социальные институты нуклеарной семьи, школы, армии, тюрьмы, клиники, церкви. На протяжении истории государство бескомпромиссно искореняло всяческое несогласие, предписывая ограничения на сословные браки, изолируя душевнобольных, наказывая преступников, муштруя армию, дисциплинируя школу и т. д.

Антропология Фуко строится на неотделимости рациональности от телесности. Каждому типу рациональности соответствует свое представление о человеке и отношение к опыту телесного существования. В эпоху Ренессанса и господства пантеистических моделей космоса (Н. Кузанский, Д. Бруно) Разум приобретал статику идеальных, совершенных тел, изображаемых искусством и литературой, как воплощенной мечте человечества.

В Новое время классический рационализм ставил мысль превыше тела. Разум становится воспитательной, наказывающей и даже излечивающей силой по отношению к зависимому телу. В книге «История безумия в классическую эпоху» (1961г.) Фуко исследует законодательные и институциональные формы изоляции и врачевания больных тел в Новое время. Недуг слабоумия был признаком неразумности и требовал своего исправление. Если безумец неизлечим, то его страждущее тело в назидание выставляли напоказ для демонстрации порока. В преследовании душевнобольных роль общественных установлений была двоякой: «Как ни странно, именно рационализм допустил, чтобы наказание смешалось с лекарством, а жест карающий почти полностью отождествился с жестом врачую- 
щим» [8, с. 101]. В книге «Надзирать и наказывать» (1975 г.) Фуко прослеживает историю законодательства по созданию исправительных учреждений для преступников во Франции в XVIII-XIX веках. До формирования современной системы судопроизводства только публичность казней и пыток была устрашающей мерой, свидетельствующей о неотвратимости наказания. Современное правосудие должна вести не столько к устрашению, сколько к искоренению преступных наклонностей, раскаянию правонарушителя в содеянном. Для этих целей государство последовательно создает систему исправительных учреждений - тюрем, каторжных работ, арестантских домов, казематов - по формированию послушных и дисциплинированных тел, признанных преступниками. Власть ищет рациональные формы по предупреждению и устранению опасных отклонений личности, ведущих к нарушению правовых норм. Однако, по наблюдениям Фуко, сформированная машина наказания и всеподнадзорности не привела к перевоспитанию заключенных или уменьшению числа рецидивистов. Самим фактом написания этих работ М. Фуко выражает свой протест против классической формы рациональности, насаждающей абсолют нормальности. За внешним лингвистическим тождеством слова и вещи стоит аксиома рационального дискурса, строжайше регламентирующая общественную жизнь, не допускающая инакомыслия, индивидуальности, свободы воли. Альтернативой классической рациональности может стать современная эпистемология, рассматривающая язык как диалог различных дискурсов и свободу интерпретаций. При этом его взаимодействие с социальной средой носит характер обратной связи: не шаблонная теория организует реальность, а продуктивный диалог, столкновение разных точек зрения формируют особый тип мышления, способного к продуктивному развитию. Особенно наглядно столкновение этих двух ментальных типов проявляется на начальных ступенях формирования человека, в процессе воспитания. Размежевание авторитарной и демократической модели воспитания для Фуко имеет, конечно, политический контекст: «Любая система образования является политическим способом поддержания 
или изменения форм присвоения дискурсов - со всеми знаниями и силами, которые они за собой влекут» [6, с. 74].

Эпоха рационализма наложила свой неповторимый отпечаток на организацию педагогического процесса в военных и церковно-приходских школах XVIII века. В книге «Надзирать и наказывать» рассматривается феномен появления в это время французских, так называемых, «нормальных» школ. Документы об организации воспитания в эпоху Просвещения очень далеки по своему содержанию от тех художественных фантазий, которым, к примеру, предавался Ж.-Ж. Руссо в своих наставлениях Эмилю. В XVIII в. в обществе появился суровый воспитатель со своими правилами и стандартами поведения под названием Разум. Приказы этого надзирателя отличались краткостью и ясностью, как военная команда. За ним, безо всякого обсуждения или повторения, должно следовать немедленное и заранее установленное реагирование. Единственно правильный ответ и механическое исполнение по своему характеру напоминал инстинктивную поведенческую связь «сигнал-реакция».

Воспитание школьника начинается с изучения им системы словесных или жестовых сигналов учителя, каждый из которых предполагает соответствующее действие. Наказание или порицание становится для воспитуемого главным стимулом к учебе. Любознательность, проявление самостоятельности или дополнительные вопросы в такой системе становятся второстепенными, иногда негативными. Один ученик своими знаниями и одеждой похож на другого, а все вместе - единому среднему стандарту. Изготовление всевозможных ортопедических приспособлений, введение режима для страдающих дистрофией и т. п. были не единственными мерами по предупреждению порицаемого неравенства. Для послушных и аккуратных учеников не похожий на них нарушитель тоже представляет угрозу, противопоставляя себя им, поэтому в церковно-приходских школах часто прибегали к методу взаимного обучения и воспитания. Обо всех непристойных проступках учеников вне школы становилось немедленно известно учителю. Это усиливало контроль за воспитанниками, препятствовало образованию 
неформальных групп и укрепляло институт наушничества. Донос поощрялся, так как оказывал помощь учителю или следящему за порядком. Образцовым учеником объявлялся тот, кто не только заучивает предписанный материал, но и покорен правилам, установленным учителем. Детям внушается, что разумный индивид обязан знать минимум обязательных знаний, а иначе он будет подвергнут наказанию и отлучён от разумного сообщества.

Детская индивидуальность предписывается учителем, а после этого она оценивается и документируется. Ребёнок выключен из системы идентификации, оставаясь покорным объектом для формирования разумного эталона. Фуко ведёт речь об особой системной индивидуальности, не имеющей ничего общего с природной или познавательной особенностью: «... индивид есть вымышленный атом «идеологического» представления об обществе; но он есть также реальность, созданная специфической технологией власти, которую я называл дисциплиной» [9, с. 284]. Современному обществу при сохранении дисциплинарного института школы такая репрессивная система подавления инициативы воспитуемого представляется не эффективной. Рациональное оформление дидактики ведет к тому, что не повторение, а творчество, не исполнение, а проблемное обучение, могут сформировать мыслящую личность. Этот новый социальный аспект меняет форму артикуляции знаний, коммуникации, целей деятельности, а в конечном итоге и вид рациональности, основывающейся на критическом осмыслении различных теоретических дискурсов [14, с. 356].

Таким образом, лингвистические формы рациональности, обозначенные Фуко еще в 60-е годы XX века, существенно дополняют устоявшиеся в философии представления о классическом и неклассическом виде научного мышления. Структурные отношения языка и вещи, исследуемые им внутри исторического и антропологического контекста, позволяют выйти за границы исключительно теоретического знания. Рациональность всегда имеет общественное значение и неотделима от господствующих в тот или иной период истории дискурсивных практик. В конце 80-х годов похожий ра- 
курс рассмотрения рациональности, но с точки зрения деятельностного подхода, задает и отечественный философ В.С. Степин. Знание не может быть объективировано по отношению к человеку и обращено в теоретическую догму. Находясь внутри природных и социальных систем, он их активно преобразует, создавая новые теоретические программы. В условиях современного информационного общества рациональные пути преобразования теоретического дискурса становятся еще более многообразными. Значимые сегодня ценности независимости мышления, свободы интерпретаций, коммуникабельности имплицитно присутствовали в каждом произведении М. Фуко, исследовавшим историческую эволюцию рациональных форм.

\section{Сиисок литературы}

1. Ионин Л.Г. Социология культуры. М.: Логос, 1996. С. 280.

2. Стёпин В.С. Классика, неклассика, постнеклассика: критерии различения // Постнеклассика: философия, наука, культура. СПб.: Издательский дом «Міръ», 2009. С. 249-295.

3. Стёпин В.С., Кузнецова Л.Ф. Научная картина мира в культуре техногенной цивилизации. М.: ИФРАН, 1994. С. 10-270.

4. Степин В.С. Типы научной рациональности и синергетическая парадигма // Сложность. Разум. Постнеклассика. 2013. № 4. С. 45-59.

5. Мамардашвили М.К. Классические и неклассические идеалы рациональности. М.: Азбука, 2010. С. 40-288.

6. Фуко М. Воля к истине: по ту сторону знания, власти и сексуальности. Работы разных лет. М.: Касталь, 1996. С. 10-448.

7. Фуко М. Интеллектуалы и власть: Избранные политические статьи, выступления и интервью / Ч.2: Статьи и интервью, 1970-1984. М.: Праксис, 2005. С. 5-320.

8. Фуко М. История безумия в классическую эпоху. СПб.: Университет, 1997. С. 30-576.

9. Фуко М. Надзирать и наказывать. М.: Ad Marginem, 1999. С. 100-479. 10. Фуко М. Ненормальные: Курс лекций, прочитан в Коллеж де Франс в 1974-1975 учеб. году. СПб.: Наука, 2005. С. 10-432. 
11. Фуко М. Рождение клиники. М.: Смысл, 1998. С. 20-310.

12. Фуко М. Слова и вещи. Археология гуманитарных наук. СПб.: A-cad, 1994. С. 59-408.

13. Фуко М. Это не трубка. М.: Издательство «Художественный журнал», 1999. С. 5-75.

14. Щеров В.И. Философия текста американского постструктурализма // В мире научных открытий. Красноярск: Научно-инновационный центр, 2013. № 11.5(47). С. 354-360.

15. Щеров В.И. Философия технических наук: учебное пособие. Смоленск: РИО филиала ФГБОУ ВО «НИУ «МЭИ» в г. Смоленске, 2018. C. 3-144.

\section{References}

1. Ionin L.G. Sociologija kul'tury [Sociology of culture]. M.: Logos, 1996. P. 280 .

2. Stjopin V.S. Postneklassika: filosofija, nauka, kul'tura [Post-non-classics: philosophy, science, culture]. SPb.: Izdatel'skij dom «Mir», 2009, pp. 249-295.

3. Stjopin B.C., Kuznecova L.F. Nauchnaja kartina mira v kul'ture tehnogennoj civilizacii [The scientific picture of the world in the culture of technological civilization]. M.: IFRAN, 1994, pp. 10-270.

4. Stepin V.S. Slozhnost'. Razum. Postneklassika. 2013. № 40, pp. 45-59.

5. Mamardashvili M.K. Klassicheskie i neklassicheskie idealy racional'nosti [Classical and non-classical ideals of rationality]. M.: Azbuka, 2010, pp. 40-288.

6. Fuko M. Volja k istine: po tu storonu znanija, vlasti i seksual'nosti. Raboty raznyh let [The will to truth: on the other side of knowledge, power and sexuality. Works of different years]. Moscow: Castal, 1996. pp. 10-448.

7. Fuko M. Intellektualy i vlast': Izbrannye politicheskie stat'i, vystuplenija i interv'ju [Intellectuals and Power: Selected Political Articles, Speeches, and Interviews]. Vol.2: Articles and Interviews, 1970-1984. M.: Praksis, 2005, pp. 5-320.

8. Fuko M. Istorija bezumija v klassicheskuju jepohu [The history of madness in the classical era]. SPb.: University, 1997, pp. 30-576. 
9. Fuko M. Nadzirat'i nakazyvat' [Oversee and punish]. Moscow: Ad Marginem, 1999, pp. 100-479.

10. Fuko M. Nenormal'nye: Kurs lekcij, prochitan v Kollezh de Frans v 1974 1975 ucheb. Godu [Abnormal: A course of lectures, read at the Collège de France in 1974-1975 studies. Year]. SPb.: Science, 2005, pp. 10-432.

11. Fuko M. Rozhdenie kliniki [The birth of the clinic]. M.: Meaning, 1998, pp. 20-310.

12. Fuko M. Slova i veschi. Arheologija gumanitarnyh nauk [Words and things. Archeology of the humanities]. SPb.: A-cad, 1994, pp. 59-408.

13. Fuko M. Jeto ne trubka [This is not a tube]. M.: Izdatel'stvo «Hudozhestvennyj zhurnal», 1999. S. 5-75.

14. Shcherov V.I. V mire nauchnykh otkrytiy [Siberian Journal of Life Sciences and Agriculture]. Krasnoyarsk: Scientific Innovation Center, 2013. № 11.5 (47), pp. 354-360.

15. Shcherov V. I. Filosofija tehnicheskih nauk: uchebnoe posobie [Philosophy of Technical Sciences]. Smolensk, 2018, pp. 3-144.

\section{ДАННЫЕ ОБ АВТОРЕ}

Щеров Владимир Иванович, доцент кафедры гуманитарных наук, кандидат философских наук

Филиал «Национального Исследовательского Университета «МЭИ» в г. Смоленске

Энергетический пр-д, 1, г. Смоленск, 214013, Российская Федерачия

vladsher52@gmail.com

\section{DATA ABOUT THE AUTHOR}

Shcherov Vladimir Ivanovich, Associate Professor of Department of humanitarian sciences, Ph. D. in Philosophy

National Research University "Moscow Energy Institute" in Smolensk 1, Energetichesky passage, Smolensk, 214013, Russian Federation vladsher52@gmail.com

SPIN-code: 5890-2161

ORCID: 0000-0003-0510-3386

Researcher ID: E-5040-2019 